\title{
Using Phytoremediation with Canola to Remove Cobalt from Agricultural Soils
}

\author{
Sevinç Adiloğlu* \\ Faculty of Agriculture, Department of Soil Science and Plant Nutrition, \\ Namik Kemal University, Tekirdağ, Turkey
}

Received: 27 January 2016

Accepted: 10 March 2016

\begin{abstract}
The goal of my study is to propose an improved method for reclaiming cobalt $(\mathrm{Co})$ contamination in agricultural lands using canola (Brassica napus L.). Cobalt $\left(100 \mathrm{mg} / \mathrm{kg}\right.$ ) in the form of $\mathrm{CoSO}_{4}$ was given to each parcel. Afterward ethylenediaminetetraacetic acid (EDTA) chelate was given to every single parcel in four doses $(0 \mathrm{mmol} / \mathrm{kg}, 5 \mathrm{mmol} / \mathrm{kg}, 10 \mathrm{mmol} / \mathrm{kg}$, and $15 \mathrm{mmol} / \mathrm{kg})$ in the course of the spadix period of the plants. The plants were harvested four months after sowing. Although the quantities of available Fe, Mn, and $\mathrm{Cu}$ of the experimental area soil sample were adequate, the available $\mathrm{Zn}$ quantity was determined to be inadequate. The texture of research area soil was clay (C). In respect to the field experiment results, increasing EDTA doses had a negative affect on roots and shoots of canola plants. Furthermore, cobalt concentrations in underground parts and aboveground plant parts increased with increasing EDTA applications. These results were found to be statistically significant at the level of $1 \%$. Consequently, cobalt heavy metal contaminants of Tekirdağ country soils could be improved by the phytoremediation method as shown in this research.
\end{abstract}

Keywords: phytoremediation, heavy metals, cobalt, canola, soil pollution

\section{Introduction}

Heavy metal contamination in agricultural soil has become one of the most important environmental problems for environmental and agricultural scientists. Heavy metal contamination in agricultural soil is not only pollution, but it also has a dangerous effect on wildlife and human life. But the solution to this problem using traditional physical and chemical methods is too expensive, which is why the industrial organizations in our country have been postponing the solution to the problem.

Accumulation of heavy metals in the ecological system, as a result of fast industrilization and urbanization,

*e-mail: sadiloglu@hotmail.com has become a major threat for public health. Heavy metals such as cadmium, lead, chrome, cobalt, nickel, and copper, which are widely used in industry, are dumped into the ecological environment without any treatment. The wastes that are not treated have adverse effects on the environment and on agricultural soils [1].

Research has been conducted on how to use wheat to eliminate lead contamination in agricultural soils [2]. This research was done in greenhouse conditions. They used EDTA chelate to increase the amount of the lead absorbtion of wheat plant in the phytoremediation method. After a two-month-long experiment, lead absorbtion capacity of the plant increased with the amount of increased EDTA.

The phytoremediation method enables us to keep pollutants and radioactive substances in removable chemical forms. This is the least harmful state of the 
pollutants in terms of public health. In comparison to the other rehabilitation methods and techniques, this one is the most economical. Fertile soil conditions are created after green rehabilitation [3].

Dock plant was obtained for having a high fitoremeditation capacity, and was found by some researchers to have high accumulated heavy metals such as cobalt [4].

Some chelates used in fitoremeditation methods are complex compounds used to increse the changeability and solubility of some heavy metals within agricultural areas and increase plant absobtion capacity to take these heavy metals, i.e., $\mathrm{Co}, \mathrm{Ni}$, and $\mathrm{Cd}$ from agricultural soils [5-7].

Chelates are comprised of three constituents. They are the metal included in chelate and chelate material (EDTA, DTPA, EDDHA, amino-acid, humic acid, fulvic acid). Chelates enable a plant to take the metal from the soil, but they don't allow it to penetrate the plant [8].

For this paper I investigated phytoremediation of Co from agricultural lands handling canola (Brassica napus L.) plant.

\section{Materials and Methods}

The investigation was conducted at the Tekirdağ, between the coordinates of $40^{\circ} 59^{\prime} 43.64^{\prime \prime} \mathrm{N}-27^{\circ} 35^{\prime} 39.76^{\prime \prime}$ E from April to August. $100 \mathrm{mg} / \mathrm{kg} \mathrm{CoSO}$ was used for contaminating the fields. Each parcel size was $(3 \times 1.2 \mathrm{~m})$ : $3.6 \mathrm{~m}^{2}$ and experimental design was randomize block design and the experiment was performed in three replications. EDTA was used to increase the solubility of cobalt in the experimental area soil. Canola (Brassica napus L.) plants were used for testing because it was the most suitable hyperaccumulator plant [9]. $100 \mathrm{mg} / \mathrm{kg}$ cobalt in $\mathrm{CoSO}_{4}$ form was administered to the testing land. Later the $\mathrm{CoSO}_{4}$ was given to the experimental land and the incubation continued for 30 days to allow for the creation of the contamination in the experiment area and the absorption in the soil colloids, and then extractable amounts of the cobalt were determined in the experiment area soil samples. Canola plant seeds were sowed, and then some $0 \mathrm{mmol} / \mathrm{kg}$, $5 \mathrm{mmol} / \mathrm{kg}, 10 \mathrm{mmol} / \mathrm{kg}$, and $15 \mathrm{mmol} / \mathrm{kg}$ of ethylenediaminetetraacetic acid were given to each parcel before the flowering time of the canola plants for increasing cobalt absorption by plants. After four months the canola plants were harvested.

The extractable cobalt level of the experiment area soil was obtained by [10]. pH value, lime content, organic matter amount, and available phosphorus content of experimental area soil were determined by [11]. Cobalt concentration of the shoot and root parts of canola plant samples were determined by wet digestion method with ICP-OES [12]. Dry matter amount of the plants were determined by [12].

Statistical analysis was done using PASW Statistics 18 for windows software. ANOVA variance analysis was done on the research results and Duncan multiple comparison tests were done on these research results.
Table 1. Several features of the experiment area soil.

\begin{tabular}{|c|c|c|}
\hline Soil properties & Unit & Value \\
\hline $\mathrm{pH}$ & $(1: 2.5 \mathrm{soil}$ :water $)$ & 6.81 \\
\hline Electrical Conductivity & $\mathrm{dS} / \mathrm{m}$ & 128.3 \\
\hline $\mathrm{CaCO}_{3}$ & $\%$ & 2.40 \\
\hline Organic matter content & $\%$ & 1.88 \\
\hline $\mathrm{P}_{2} \mathrm{O}_{5}$ & $\mathrm{~kg} / \mathrm{da}$ & 11.42 \\
\hline $\mathrm{K}_{2} \mathrm{O}$ & $\mathrm{kg} / \mathrm{da}$ & 25.32 \\
\hline $\mathrm{Fe}$ & $\mathrm{mg} / \mathrm{kg}$ & 3.46 \\
\hline $\mathrm{Cu}$ & $\mathrm{mg} / \mathrm{kg}$ & 0.63 \\
\hline $\mathrm{Zn}$ & $\mathrm{mg} / \mathrm{kg}$ & 0.40 \\
\hline $\mathrm{Mn}$ & $\mathrm{mg} / \mathrm{kg}$ & 5.72 \\
\hline $\mathrm{Co}$ & $\mathrm{mg} / \mathrm{kg}$ & 0.08 \\
\hline $\mathrm{Clay}$ & $\%$ & 42.98 \\
\hline $\mathrm{Silt}$ & $\%$ & 25.44 \\
\hline $\mathrm{Sand}$ & & 31.58 \\
\hline
\end{tabular}

\section{Results and Discussion}

The available manganese, copper, and iron contents obtained adequate levels but available $\mathrm{Zn}$ content of the research area soil was determined to be deficient, and texture class was obtained by clay texture [13-14]. pH value was neutral, lime content was low, and organic matter content of soil samples was insufficient. The plant available phosphorus and exchangeable potassium amounts were adequate (Table 1). The extractable cobalt concentration of the soil sample was obtained as $0.08 \mathrm{mg} / \mathrm{kg}$ for the initial experiment and as $2.25 \mathrm{mg} / \mathrm{kg}$ later after 30 days of the incubation experiment.

EDTA application on the dry matter amount and mean values dry matter amount of root and shoot parts of canola plant are shown in Tables 2 and 3.

The effects of chelate application on the dry matter amount of root and trunk parts of the canola plant were deemed important at the level of $1 \%$, statistically (Table 2).

According to Table 3, the maximum dry matter yield in the roots and shoots of the canola was determined as $0 \mathrm{mmol} / \mathrm{kg}$ EDTA given dose, and the determined dry matter proportion is $700 \mathrm{~kg} / \mathrm{da}$ in the root part and $980 \mathrm{~kg} / \mathrm{da}$ in the shoot part. On the other hand, the minimum dry matter yield was determined in $15 \mathrm{mmol} / \mathrm{kg}$ EDTA given dose, and these values were of $485 \mathrm{~kg} / \mathrm{da}$ and $570 \mathrm{~kg} / \mathrm{da}$ for the root part and shoot part of the canola plant. Besides, the effects of EDTA application on the dry matter amount of the canola plant were determined to be significant at the level of $1 \%$, statistically (Table 2). Duncan multiple comparison test was applied and the cobalt concentations of the root and shoot parts of canola plants were classified into different groups. 
Table 2. F value from analysis of variance measured on dry matter amount.

\begin{tabular}{|c|c|c|c|c|c|c|c|}
\hline SV & df & $\begin{array}{c}\text { SS } \\
\text { root }\end{array}$ & $\begin{array}{c}\text { MS } \\
\text { root }\end{array}$ & Fvalue root & $\begin{array}{c}\text { SS } \\
\text { shoot }\end{array}$ & $\begin{array}{c}\text { MS } \\
\text { shoot }\end{array}$ & $\begin{array}{c}\text { F value } \\
\text { shoot }\end{array}$ \\
\hline General & 14 & $87,266.0$ & & & $269,928.0$ & & \\
\hline EDTA dose & 4 & $87,150.0$ & $21,787.0$ & $0.001^{* *}$ & $269,760.0$ & $67,440.0$ & $0.001^{* *}$ \\
\hline Error & 10 & 116 & 11.6 & & 168 & 16.8 & \\
\hline
\end{tabular}

SV: source of variation, df: degree of freedom, SS: sum of squares, MS: mean of squares, F: F value ** and *: significant at $1 \%$ and $5 \%$, ns: non-significant

Table 3. Average data and significance groups of chelate on dry matter amount of canola $(\mathrm{kg} / \mathrm{da}) *$.

\begin{tabular}{|c|c|c|}
\hline EDTA Applications & Cobalt (Co)Root & Shoot \\
\hline Control & $680 \pm 3.21 \mathrm{~d}$ & $975 \pm 3.21 \mathrm{~d}$ \\
\hline $0 \mathrm{mmol} / \mathrm{kg}$ & $700 \pm 0.57 \mathrm{e}$ & $980 \pm 1.52 \mathrm{~d}$ \\
\hline $5 \mathrm{mmol} / \mathrm{kg}$ & $648 \pm 2.08 \mathrm{c}$ & $860 \pm 4.04 \mathrm{c}$ \\
\hline $10 \mathrm{mmol} / \mathrm{kg}$ & $590 \pm 3.28 \mathrm{~b}$ & $660 \pm 3.51 \mathrm{~b}$ \\
\hline $15 \mathrm{mmol} / \mathrm{kg}$ & $485 \pm 2.51 \mathrm{a}$ & $570 \pm 2.00 \mathrm{a}$ \\
\hline
\end{tabular}

*The value mean of three replications and roots and shoots were evaluated individually.

The effects ofEDTAapplication on the Co concentration of plant parts of the canola plant were determined to be significant at the level of $1 \%$, statistically (Table 4 ).

The effects of EDTA application on cobalt concentrations of roots and shoots of canola plants and statistical analysis data are shown in Tables 4 and 5.

According the these results, cobalt concentrations in parts of the canola plant increased with increasing doses of EDTA(Table 5). The reason for these results may be that the EDTA increased the solubility and availability of cobalt in the experiment area soil. Therefore, the absorption of cobalt by the plant increased. Minimum cobalt concentrations in shoot and root parts of canola were obtained as $0 \mathrm{mmol} / \mathrm{kg}$ EDTA given to the soil. On the other hand, maximum cobalt concentration of canola shoots and roots were determined with $15 \mathrm{mmol} \mathrm{kg}^{-1}$ EDTA given to the experiment area soil. These results have been found by some earlier researchers, who found that EDTA applications to soil increased the solubility and absorbability of the cobalt metal in the soils and the uptake of the cobalt heavy metal from the
Table 5. Average data and significance groups of chelate on cobalt $(\mathrm{Co})$ concentrations in canola $(\mathrm{mg} / \mathrm{kg})^{*}$.

\begin{tabular}{|c|c|c|}
\hline EDTA Applications & Cobalt (Co) Root & Shoot \\
\hline Control & $1.95 \pm 0.02 \mathrm{a}$ & $2.18 \pm 0.04 \mathrm{a}$ \\
\hline $0 \mathrm{mmol} / \mathrm{kg}$ & $13.30 \pm 0.08 \mathrm{~b}$ & $11.56 \pm 1.39 \mathrm{~b}$ \\
\hline $5 \mathrm{mmol} / \mathrm{kg}$ & $28.60 \pm 1.50 \mathrm{c}$ & $24.45 \pm 0.59 \mathrm{c}$ \\
\hline $10 \mathrm{mmol} / \mathrm{kg}$ & $51.40 \pm 2.61 \mathrm{~d}$ & $39.12 \pm 1.14 \mathrm{~d}$ \\
\hline $15 \mathrm{mmol} / \mathrm{kg}$ & $75.40 \pm 1.56 \mathrm{e}$ & $45.20 \pm 0.60 \mathrm{e}$ \\
\hline
\end{tabular}

*: The data mean of three replications and root and shoot parts of canola plant were utilized independently.

soil by some plants [15-19]. Besides, the effects of EDTA applications on cobalt concentrations of canola roots and shoots are shown in Fig. 1.

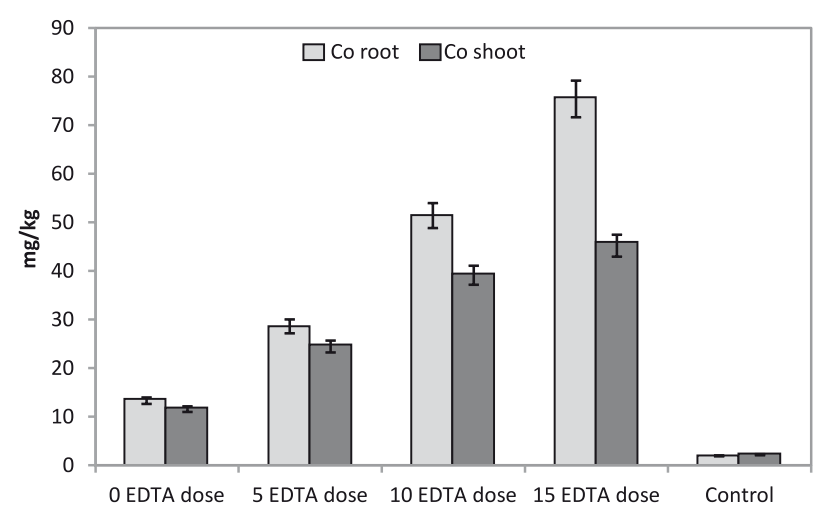

Fig. 1. The effect of EDTA applications on the amount of cobalt in canola plants.

Table 4. F value from analysis of variance for measured amounts of cobalt concentration of canola plants.

\begin{tabular}{|c|c|c|c|c|c|c|c|}
\hline SV & df & $\begin{array}{c}\text { SS } \\
\text { root }\end{array}$ & $\begin{array}{c}\text { MS } \\
\text { root }\end{array}$ & Fvalue root & $\begin{array}{c}\text { SS } \\
\text { shoot }\end{array}$ & $\begin{array}{c}\text { MS } \\
\text { shoot }\end{array}$ & $\begin{array}{c}\text { F value } \\
\text { shoot }\end{array}$ \\
\hline General & 14 & $10,574.0$ & & & $3,947.5$ & & \\
\hline EDTA dose & 4 & 10,504 & 2626.1 & $0.001^{* *}$ & $3,923.5$ & 980.8 & $0.001^{* *}$ \\
\hline Error & 10 & 69.5 & 6.9 & & 23.9 & 2.3 & \\
\hline
\end{tabular}

SV: source of variation, df: degree of freedom, SS: sum of squares, MS: mean of squares, F: F value ** and *: significant at $1 \%$ and $5 \%$, ns: non-significant 
According to Fig. 1, cobalt concentrations in parts of the canola plant increased with increasing the EDTA given to experiment area soil. On the other hand, increasing cobalt concentrations in the roots and shoots of the canola plant reached a statistically significant level at $1 \%$, and significantly different groups were formed in a Duncan multiple comparison test.

\section{Conclusion}

EDTA applications positively affected cobalt concentrations in canola shoots and roots, and results showed that cobalt concentrations in canola plants increased with increasing EDTA applications to the experiment area soil. But dry matter amounts of shoot and root parts of canola decreased with cobalt and increasing rates of EDTA applications to the experiment area soil. On the other hand, these increases and decreases reached significance at the level of $1 \%$ for Cobalt and EDTA applications to the experiment area soil. This result was expected because the increasing rate applications of EDTA chelate increases the solubility of the heavy metals, i.e., cobalt, and enables the plants to absorb this heavy metal. This experiment showed that cobalt was removed from canola plants grown in agricultural soils using phytoremediation.

\section{References}

1. GAVRILESCU M. Removal of Heavy Metals from Environment by Biosorption. Eng. Life Sci. 4 (3), 219, 2004.

2. SAIFULLAH A.G., QUADIR M. Lead Phytoextraction by Wheat in Response to the EDTA Application Method. International J. of Phytoremediation, 11, 268, 2009.

3. KÖSEOĞLU C. An Investigation on Phytoremediation Methods of Sweadge Sludge. Çukurova University Graduate School of Natural and Applied Sci. MSc thesis, Adana. 2007.

4. BAHTIYARCA BAĞDAT R., EID E.M. Phytoremedation Behaviour of Some Medicinal and Aromatic Plants to Various Pollutants. J. of Central Research Institute For Field Crops. 16, 1, 2007.

5. NOWACK B., KARI F.G., KRÜGER H.G. The Remobilization of Metals from Iron Oxides and Sediments by Metal-EDTA Complexes. Water, Air and Soil Poll. 125, 243, 2001.
6. ADILOĞLU S., SAĞLAM M.T., ADILOĞLU A., SÜME A. Removal of Nickel (Ni) from Agricultural Field Soils by Phytoremediation using Canola (Brassica napus L.). Desalination and Water Treatment. 57 (6), 2383, 2016.

7. ADILOĞLU S., ADILOĞLU A., ERYILMAZ AÇIKGÖZ F., YENIARAS T., SOLMAZ Y. Phytoremediation of Cadmium From Soil Using Patience Dock (Rumex patientia L.) Analytical Letters. 49, 601, 2016.

8. HOVSEPYAN A. GREIPSSON S. EDTA Enhanced Phytoremediation of Lead-Contaminated Soil by Corn, Journal of Plant Nutrition. 28, 2037, 2005.

9. DINÇ B.E. An Investigation on Yield and Yield Components of Canola Plant. Namik Kemal University Graduate School of Natural and Applied Sciences. Master Thesis, 136, 2010.

10. LINDSAY W.L., NORVELL W.A. Development of a DTPA Soil Test for Zinc, Iron, Manganase and Copper. Soil Sci. Soc. Am. J. 42, 421, 1978.

11. SAĞLAM M.T. Chemical Analysis Methods of Soil and Water. Namık Kemal University, Publ. 2, 220, 2012.

12. KACAR B., INAL A. Plant Analysis, Nobel Publ. 1241, Ankara, 2010.

13. ALPASLAN M., GÜNEŞ A., İNAL A. Experiment Techniques. A.Ü. Agricultural Faculty Publ. 1501, Ankara. 2005.

14. FAO. Micronutrient, Assesment and the Country Level: An International Study. FAO Soils Bulletin 63, 218, 1990.

15. ESRINGÜ A. Removing of Some Heavy Metals from the Soil with Canola (Brassica nopus) and Mustard. Atatürk University, Graduate School of Natural and Applied Sciences. Master Thesi. 86, 2005.

16. KARAMAN M.R., ADILOĞLU A., BROHI R., GÜNEŞ A., INAAL A., KAPLAN M., KATKAT V., KORKMAZ A., OKUR N., ORTAŞ İ., SALTALI K., TABAN S., TURAN M., TÜFENKÇI Ş., ERASLAN F., ZENGIN M. Plant Nutrition. Dumat offset, 1080, 2012.

17. ÇAKMAKCI T., UCAR Y. Efficiency of Canola (Brassica Napus L.) as an Accumulator of Heavy Metals in Wastewater Applications. Pol. J. Environ. Stud. 23, 2309, 2014.

18. STINGU A., VOOLF I., ROBU B., POPA V. Phytoremediation potential of Brassica napus in heavy metal polluted environment. International Conference on Environmental Pollution and Clean/Phytoremediation, 16-19 June, Pisa, Italy, 2010.

19. ADILOĞLU S., SAĞLAM M.T., SÜME A. Chrome (Cr) Pollution In Agricultural Areas Improvement By Phytoremediation Method With Canola (Brassica Napus L.) Plant Growing. Journal of Essential Oil Bearing Plants 18, $1180,2015$. 